Further study of these epidemiological changes is required.

HELEN SMITH
Locum consultant in public health medicine

Department of Public Health,

Argyll and Clyde Health Board,

Paisley PA2 7BN

DAVID HALI

Mental Welfare Commission for Scotland,

Edinburgh EH3 7RN

1 Beck P, Lazarus J, Scorer R, Smith P, Routledge P. Increasing

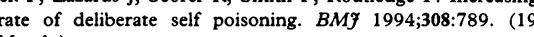
March.)

2 Nordentoft $M$, Breum L, Munck LK, Nordestgaard AG, Hunding A, Bjaeldager PAL. High mortality by natural and unnatural causes: a 10 year follow up study of patients admitted to a poisoning treatment centre after suicide attempts. $B M F$ 1993;306:1637-41.

3 Hawton K, Fagg J. Suicide, and other causes of death, following attempted suicide. Br f Psychiatry 1988;152:359-66.

4 Crombie IK. Suicide in England and Wales and in Scotland. A examination of divergent trends. Br F Psychiatry 1990;157: examination.

\section{Fibrin glue}

EDIToR,-H I Atrah's editorial on fibrin glue draws attention to the limited use of fibrinogenthrombin formulations in surgical procedures especially in Britain and the United States, even though such formulations have been commercially available since the early 1970 s. $^{1}$ The explanation forwarded for this is "concern about safety and unawareness of potential applications."

I do basic research into fibrinogen and have noticed more than 1000 publications in the Medline database referring to the clinical uses of fibrin sealants in a wide range of surgical procedures. Though many of these are single case reports or reports of small series of patients, most describe the suitability of fibrin sealant for the application under investigation (haemostasis, adhesion, air leakage, gut or nerve anastomosis, sealing, etc). Unfortunately, few controlled trials have included sufficient numbers of patients and used objective end points (for example, a reduction in blood used or lost during a defined cardiothoracic procedure) to test the cost-benefit value of fibrin sealant.

"Concern about safety" weighed heavily with the Food and Drug Administration's decision to limit fibrinogen concentrates prepared from many hundreds of pooled plasma donations from the American market in the early 1970s. Vira inactivation by ultraviolet irradiation or detergen cleansing still has not restored total confidence in pooled plasma preparations, especially as companies may ignore guidelines ${ }^{2}$ and new infective agents, such as HIV-c, are being recog nised.

The shift from bovine to human thrombin has indeed avoided the most apparent problems associated with antigenic reactivity and induction of immune haemorrhagic diatheses but has not removed the risk introduced by thrombin as a thrombotic agent. The safety issues associated with bovine aprotinin, a plasmin inhibitor added to prolong the in vivo life of the fibrin sealant, was not addressed. Like bovine thrombin, bovine aprotinin is a source of foreign protein which may induce antigenic responses or represent a potentia source of diseases derived from cattle, such as bovine spongiform encephalopathy or bovine immune deficiency.

These safety issues are not really resolved by autologous donation (cryoprecipitation or ethanol precipitation of fibrinogen) as suggested, since currently there are no autologous replacements for thrombin or aprotinin. This may be partially solved when approved supplies of recombinant materials are available. Currently available sealants still cannot be given a totally clean bill of health

I contend that in addition to the lack of general availability the reason why fibrin sealants have not entered surgical use in the United States or Britain to the extent that the literature predicted is that the present formulations are inconvenient to prepare and deliver. The commercial freeze dried fibrinogen concentrates are often difficult to dissolve, occasionally clot before use, are difficult to deliver in a controlled fashion that does not result in repeated blockage of the needle or spray, and deliver a sealant that is too concentrated and difficult to manipulate. Cryoprecipitation results in a preparation of variable concentration and performance and, for autologous donation, requires at least 24 hours' preparation time and still depends on exogenous thrombin.

The benefits of fibrin sealants to surgery will not be fully realised until the issues of convenience of preparation (by blood bank or surgeon) and reliable delivery are solved.

$S$ A CEDERHOLM-WILLIAMS

Oxford Bioresearch Laboratory

Oxford Science Park

Oxford OX4 4GA

1 Atrah HI. Fibrin glue. BMF 1994;308:933-4. (9 April.)

2 Gedge R. German AIDS scandal infects Europe. BMF 1993;307: 1229.

\section{Long acting methods of contraception}

EDrToR,-Who could disagree with Lawrence Mascarenhas's statement that long acting contraceptive methods have much to offer?' One of these, the six capsule subdermal implant releasing levonorgestrel, was introduced to Britain last autumn. It seemed to be immediately disowned by all agencies that fund services. This was unfortunate. It is a highly effective, safe, and readily reversible long term method of contraception and could have a real impact on reducing unwanted pregnancies. Continuation rates are acceptable compared with those for oral contraception, and "user error" is not a feature. This is crucially important. Finally, although the implant is more expensive than most other methods, there should not be serious doubt about its cost effectiveness with appropriate use.

Doctors should therefore be in a position to provide and promote the implant. More importantly, it should be easily accessible to women. Yet, as Mascarenhas points out, "wranglings" stand in the way of its effective provision. The question is not whether the NHS should provide the implant. This is beyond doubt. The argument is about who should provide the method. In the brave new health service no one body has accepted responsibility for this.

Should family health services authorities fund general practitioners to provide the implant? Should district health authorities fund community trusts to provide it in clinics? The answer to both these questions has to be "yes." General practitioners are responsible for providing the bulk of family planning services. Surely most of them would wish to provide a full range of contraceptive services. Government policy clearly states that people should have a choice of outlet and that community services should offer complementary, more specialised services that target the young. ${ }^{23}$ The cost would probably not be greatly different whichever service provided the implant. An appreciable and finite minority of women would choose the implant; if it was not available they would probably still incur costs to reproductive health services.

The demise of the implant, before it has even had a chance to prove itself, seems possible. The responsibility for this must lie with those who have underfunded the health service, created divisions within it, and surrendered to "short termism."
Clinicians can only share the pain, anger, disappointment, and powerlessness of their women patients. Lichfield,

Staffordshire

1 Mascarenhas L. Long acting methods of contraception. BMf 1994;308:991-2. (16 April.)

2 Department of Health. The health of the nation. London: $\mathrm{DoH}$ 1992.

3 NHS Management Executive. Guidelines for reviewing family planning services. Leeds: NHSME, 1992.

\section{Ethics and euthanasia}

\section{Opinion polls not decisive}

EDITOR,-The emotive tone and inaccurate reporting in Madeleine Simms's letter are good examples of why the objective, dispassionate, and rigorous House of Lords Select Committee on Medical Ethics unanimously rejected euthanasia. Simms states that in a survey carried out in April last year by National Opinion Polls " $79 \%$ wanted the law to be changed to legalise voluntary euthanasia," and she then quotes correctly from the question asked. But the question asked of the public began, "Some people say that the law should allow adults to receive medical help to peaceful death." ${ }^{\prime 2}$ There was no mention of voluntary euthanasia-indeed, the question could be referring to good palliative care. The Lords committee probed this point with those members of the Voluntary Euthanasia Society who gave evidence to it; in its report the committee concluded that "the results of the public opinion polls which the [Voluntary Euthanasia Society] . . . cited are far from decisive." ${ }^{3}$

The issue of the $B M \mathcal{F}$ containing Simms's letter also contains a news article from the Netherlands on the policing of cases of euthanasia there. ${ }^{4}$ The number of cases investigated by local prosecutors is given and was "one in 1991." We do not know how many cases of euthanasia took place in the Netherlands in 1991, but we do know from a report by the Dutch government that in 1990 there were 2300 cases of active termination of life by a doctor at the request of the patient, 400 cases of suicide assisted by a doctor, and more than 1000 cases of "life terminating acts without explicit request." Does the investigation of one case or thereabouts give any reassurance in the light of these numbers?

Fourteen members of the House of Lords, including two doctors and a nurse, spent a year thoroughly investigating the situation in Britain the Netherlands, and elsewhere. Their conclusions carry a great deal more weight than those of Simms.

ANDREW FERGUSSON

Healthcare Opposed to Euthanasia,

London SE11 5TN

1 Simms M. Ethics and euthanasia. BMF 1994;308:1165. (30 April.)

2 National Opinion Polls. Survey NOP/41431, London: NOP, 1993.

3 Select Committee on Medical Ethics. Report. London: HMSO 1994. (Paragraph 101.)

4 Sheldon T. Dutch prosecutors get tough on euthanasia. BM 1994;308:1119-20. (30 April.)

5 Van der Maas PJ, van Delden JJM, Pijnenborg L, Remmelink J. Euthanasia and other medical decisions concerning the end of life. Amsterdam: Elsevier, 1992

\section{Legislation will not solve problem}

EdrTor,-I was very sad to see the letter by Madeleine Simms. ${ }^{1}$ So much has been written on voluntary euthanasia by people who are actively involved with those who are dying; it is sad to see that there is still this polarisation of views and no movement forward.

There will always be the occasional problem, but 